\title{
THE EFFECT OF MODIFIED LINEAR VISCOELASTIC IMPACT MODELS ON THE POUNDING RESPONSE OF A BASE-ISOLATED BUILDING WITH ADJACENT STRUCTURES
}

\author{
Eftychia A. Mavronicola ${ }^{1 *}$, Panayiotis C. Polycarpou ${ }^{1}$, Petros Komodromos ${ }^{1}$ \\ ${ }^{1}$ Department of Civil and Environmental Engineering, University of Cyprus \\ 75 Kallipoleos Street, P.O. Box 20537, 1678 Nicosia, Cyprus \\ \{mavronicola.eftychia, ppanikos, komodromos\}@ucy.ac.cy
}

Keywords: Seismic isolation, Structural pounding, Impact models, Kelvin-Voigt model, Seismic gap.

\begin{abstract}
During strong earthquake excitations, base-isolated buildings may collide, either with the surrounding moat wall or with adjacent buildings. This unfavorable possibility has been recently investigated through numerical simulations and parametric studies. A very important issue regarding these numerical studies is the modeling of impacts, which are typically simulated using various types of force-based impact models. This paper parametrically investigates the effects of impact modeling characteristics on the overall structural response of a base-isolated building that is subjected to seismic pounding. Specifically, the KelvinVoigt impact model and various other modifications of this linear viscoelastic impact model are considered in the performed analyses. In order to effectively and efficiently conduct this investigation, a specialized software application, which has been specifically developed to simulate buildings subjected to pounding, is employed. A smooth bilinear (Bouc-Wen) model is used for the simulation of the seismic isolation system. The influence of particular impact parameters, as well as the width of the seismic gap, on the dynamic response of the structure under strong excitations is quantified. Furthermore, the effect of using different impact models for the calculation of the impact forces on the overall seismic response during pounding is simulated and discussed, since a reasonable question arises regarding the accuracy of an impact model, which is a simplification of the actually very complicated impact phenomenon.
\end{abstract}




\section{INTRODUCTION}

Seismic isolation is widely considered as an efficient technology to improve the seismic performance of structures [1-3]. Although base isolation decreases the possibility of damage to a building, it induces large relative displacements at the isolation level. To accommodate the expected large relative displacements, a wide seismic gap must be provided around the building. This requirement imposes, a practical constraint for the utilization of seismic isolation, considering that there are often certain restrictions to the size of the available clearance around seismically isolated buildings, especially in cases of retrofitting of existing buildings in densely resided civic centers. Therefore, a reasonable concern is the risk of structural pounding with the surrounding moat wall or adjacent structures during strong earthquakes.

Earthquake-induced structural pounding on base isolated structures has been studied by several researchers the last few years. Nagarajaiah and Sun [4] observed that the response of the base-isolated Fire Command and Control Building in Los Angeles during the 1994 Northridge earthquake was altered significantly due to the occurrence of impact in the one direction, reducing the effectiveness of base isolation in that direction. Malhotra [5] and Tsai [6] examined the response of a base-isolated structure pounding against the surrounding moat wall. The superstructure was idealized as a rigid shear beam structure colliding on an adjacent retaining wall modeled as a spring element. Matsagar and Jangid [7] investigated the seismic pounding of a multi-storey building supported on various base isolation systems during impact with adjacent structures, while impacts were assumed to happen only at the base of the building with the moat wall. Komodromos et al. [8] and Komodromos [9] investigated, through parametric studies, the effects of poundings of a base isolated building with the surrounding moat wall, revealing the potentially detrimental effects of structural impact on the effectiveness of seismic isolation. Limited research works have been conducted considering three-dimensional (3D) earthquake-induced structural pounding, apparently because of the involved complexities and the consequently excessive computational cost. Pant and Wijeyewickrema $[10,11]$ studied seismic pounding of a typical 4-storey base-isolated building with retaining walls at the base using 3D finite element analyses. More recently, Polycarpou et al. [12] presented a novel methodology for simulating earthquake-induced pounding of buildings that are modeled as 3D multi-degree of freedom systems.

A critical aspect in numerical simulations of structural pounding is the impact model that is employed and the values of the associated parameters, which may affect the computed results. In most research studies on structural pounding, force-based impact models are used, exerting impact forces to the colliding structures whenever their separation distances are exceeded. Anagnostopoulos [13], Jankowski [14], Komodromos et al. [8], Ye et al. [15], Pant and Wijeyewickrema [10] and others [16-18], have proposed various methodologies using either a linear or a non-linear impact spring together with an energy dissipation mechanism to model structural pounding.

This paper describes four linear impact models that have been proposed in the literature and contrasts their performances through dynamic analyses of a typical 3-storey seismically isolated building, which is subjected to a set of near-fault ground motions. Simulation results are presented while varying several parameters, such as the size of the seismic gap and impact characteristics. The objective of this research work is to investigate how the peak seismic response of base isolated buildings during pounding may be affected by the type of the incorporated impact model. Therefore, a discussion on the deviation of the peak absolute floor accelerations and inter-storey deflections during poundings is presented, considering as base values the peak response predicted by the classical linear viscoelastic (Kelvin-Voigt) model. 


\section{MODELING AND SIMULATION ASSUMPTIONS}

It is a common practice to consider structural impacts using force-based approaches, also known as penalty methods. These methods allow some interpenetration between the colliding structures, which can be justified by local deformability at the contact point. Contact springs are automatically formed as soon as an impact is detected, kept active while the colliding bodies remain in contact and removed once the bodies are detached from each other. At each time step, the interpenetration depth, $\delta(t)$, is used together with the stiffness of the contact spring to assess, according to the adopted impact model, the contact forces that should be applied to the structures. In this research work, various linear impact models proposed in the literature are used, in order to investigate the effect of the impact model selection on the peak seismic response considering pounding incidences. Specifically, the classical Kelvin-Voigt model has been selected as a base reference, using the formulas provided by Anagnostopoulos [13] for the estimation of the impact damping coefficient. In addition, three variations of the KelvinVoigt model are discussed and compared with each other with respect to the computed peak responses through parametric studies under strong earthquake excitations with low frequency content.

\subsection{Impact modeling}

The classical Kelvin-Voigt model is commonly used to model the impact force generated between two colliding structures. The Kelvin-Voigt model consists of a linear spring and a damper, acting in parallel, in order to simulate the energy loss due to permanent deformation at the contact point, as shown in Figure 2(a). The forces in the contact element, which has been used by Anagnostopoulos [13], can be calculated through the equation:

$$
F_{\text {imp }}(t)=k_{k} \cdot \delta(t)+c_{k} \cdot \dot{\delta}(t)
$$

Considering two impacting masses, a relationship may be found between the dashpot constant $c_{k}$ and the coefficient of restitution e. The resulting mathematical expression for the damping coefficient according to this linear viscoelastic model can be assessed as:

$$
c_{k}=2 \cdot \xi_{k} \sqrt{k_{k} \cdot \frac{m_{1} \cdot m_{2}}{m_{1}+m_{2}}}
$$

where the impact stiffness $\mathrm{k}_{\mathrm{k}}$ is determined based on the axial stiffness of the colliding bodies and the impact damping ratio $\xi_{\mathrm{k}}$ is given by the following expression:

$$
\xi_{k}=-\frac{\ln \mathrm{e}}{\sqrt{\pi^{2}+(\ln \mathrm{e})^{2}}}
$$

The viscous impact damper of the Kelvin-Voigt element dissipates energy throughout the approach and restitution phases, but in reality, most of the energy dissipation takes place during the approach period and less energy is dissipated during the restitution phase. Furthermore, this model exhibits an initial jump in the impact force values due to the viscous damping term, while the damping force at the end of the restitution phase causes negative (i.e. tensile) impact forces that pull the colliding bodies together, which is unrealistic. However, due to its simplicity this model has been widely used to simulate structural pounding [19-21].

The generation of tensile forces after the detachment of the colliding bodies can be rectified through a slight adjustment of the linear viscoelastic impact model, proposed by Komodromos et al., 2007 [8], as shown in Figure 2(b). The modified viscoelastic impact model 
prevents the tensile forces, while introducing permanent plastic deformations, by zeroing the impact force when the contact is lost at the end of the restitution phase of the impact as:

$$
F_{\text {imp }}(t+\Delta t)=\left\{\begin{array}{lll}
k_{k} \cdot \delta(t)+c_{k} \cdot \dot{\delta}(t) & \text { for } & F_{\text {imp }}(t) \geq 0 \\
0 & \text { for } & F_{\text {imp }}(t)<0
\end{array}\right.
$$

Ye et al., 2009 [15] proposed a different modification to the Kelvin-Voigt impact model, as shown in Figure 2(c), noting that the Kelvin model cannot reasonably reflect the physical nature of structural pounding. That proposed model preserves the convenience in determining the linear impact spring stiffness as in the classical Kelvin-Voigt model, while the damping coefficient $\widehat{c}_{k}$ and the damping constant $\bar{\xi}_{k}$ are given by the following equations:

$$
\widehat{c}_{k}(t)=\bar{\xi}_{k} \cdot \delta(t), \quad \hat{\xi}_{k}=\frac{3}{2} \cdot \frac{k_{k} \cdot(1-e)}{e \cdot\left(v_{1}-v_{2}\right)}
$$

Another variation of the Kelvin-Voigt model was proposed by Pant and Wijeyewickrema, 2012 [10] to be used for the seismic pounding between reinforced concrete moment-resisting frame buildings (Figure 2(d)). The main difference with this modified Kelvin-Voigt model lies on the usage of a dashpot, in parallel with the spring in the contact element that is only activated during the approach period, according to the following expressions:

$$
F_{\text {imp }}(t)= \begin{cases}k_{k} \cdot \delta(t)+\bar{c}_{k} \cdot \dot{\delta}(t) & \text { for } \quad \delta(t)>0 \text { and } \dot{\delta}(t)>0 \\ k_{k} \cdot \delta(t) & \text { for } \delta(t)>0 \text { and } \dot{\delta}(t) \leq 0 \\ 0 & \text { for } \delta(t) \leq 0\end{cases}
$$

The following formulas are used for the damping coefficient and the damping constant:

$$
\bar{c}_{k}(t)=\bar{\xi}_{k} \cdot \delta(t), \quad \bar{\xi}_{k}=\frac{3}{2} \cdot \frac{k_{k} \cdot\left(1-e^{2}\right)}{e^{2}\left(v_{1}-v_{2}\right)}
$$
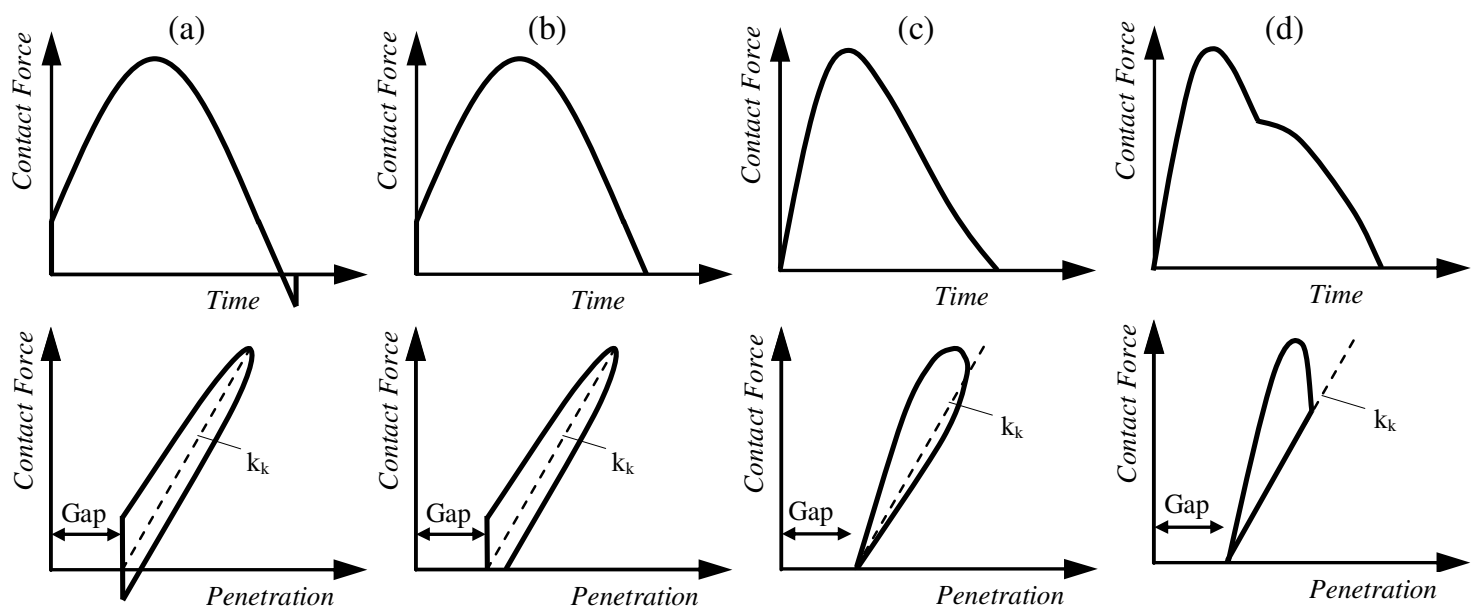

Figure 1: The linear viscoelastic impact models of (a) Anagnostopoulos, and the corresponding modified impact models proposed by (b) Komodromos et al., (c) Ye et al., and (d) Pant and Wijeyewickrema. 
Two colliding masses and a range of values of the coefficient of restitution are used in order to assess the accuracy of the aforementioned impact models. For each predefined value of the coefficient of restitution, each of the impact models is used to perform an impact simulation, compute the impact velocity after impact and, thus, the corresponding computed value for the coefficient of restitution. Figure 2 compares the pre-specified (nominal) and the computed values for the impact models under consideration, which ideally should coincide. The results show that the assumption of a direct relationship between the impact velocity and the indentation is reasonable for pre-specified coefficients of restitution larger than 0.5. Considering that for most practical purposes the coefficient of restitution for structural impact varies within the range of 0.5 to 0.75 [14], the accuracy of the proposed formulas is satisfactory.

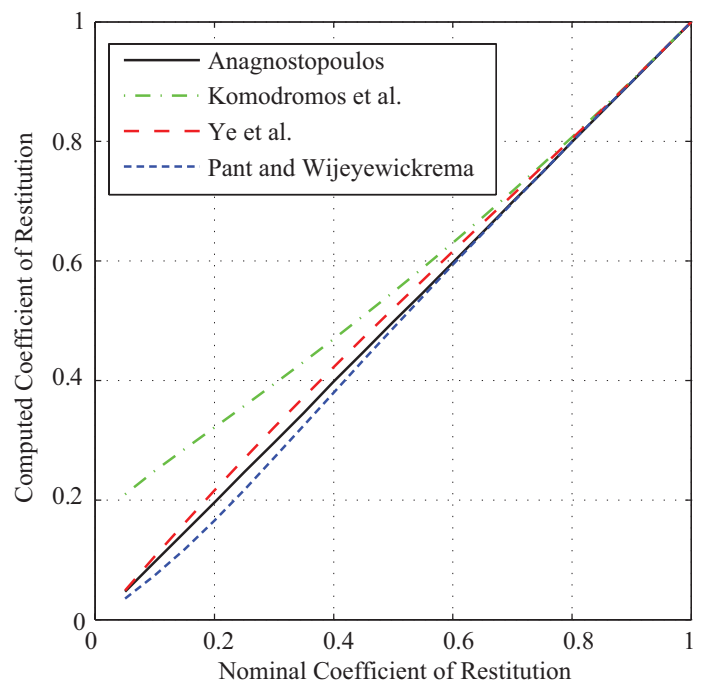

Figure 2: Comparison of the pre-specified (nominal) and computed coefficient of restitution.

\subsection{Modeling of seismically isolated buildings considering poundings}

In this study, the dynamic analyses of the simulated buildings, taking into account structural pounding, are performed in two dimensions, while the superstructure of the seismically isolated building is modeled as a shear-type structure mounted on LRBs with one lateral degree-of-freedom at each floor and the masses lumped at the floor levels, as shown in Figure 3(a). Poundings are assumed to happen between the moat wall and the base mat at the isolation level, which is the most common case of structural impact for a base isolated building due to the large relative displacements at the isolation level.

The seismically isolated MDOF system is subjected to horizontal components of near-fault ground motions, while it is assumed that the superstructure maintains a linear elastic behavior during the induced earthquake excitations. A typical 3-storey base-isolated building with 340 tons lumped mass at each floor level and a roof mass of 250 tons is used in the simulations, while a finite seismic gap on either of its sides is considered, in order to compare the estimations of the aforedescribed impact models. An additional mass of 340 tons is assumed to be lumped at the seismic isolation level. Each storey has a horizontal stiffness of $600 \mathrm{MN} / \mathrm{m}$, whereas a viscous damping ratio equal to $2.0 \%$ is assumed for the superstructure.

A smooth bilinear inelastic model is used to simulate the base isolation system (Figure 3(b)), with an isolation period based on the post-yield stiffness of 2.0 second, normalized characteristic strength $\mathrm{F}_{\mathrm{yi}} / \mathrm{W}_{\text {tot }}=10.0 \%$ and yield displacement equal to $1.0 \mathrm{~cm}$. For all performed dynamic analyses, the values 1.0, 0.5, 0.5 and 2 are adopted for the Bouc-Wen models' parameters $A, \beta, \gamma$ and $n$, respectively [22]. In addition to the hysteretic damping of the 
isolation system, a $5.0 \%$ viscous damping ratio has also been considered assuming nonclassical damping.

(a)

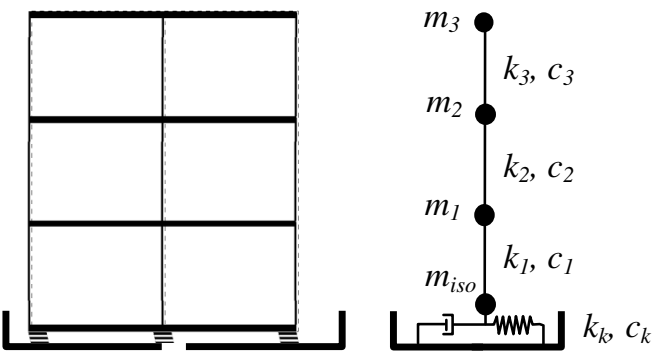

(b)

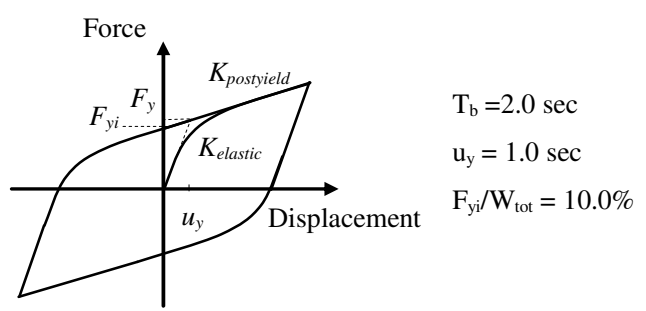

Figure 3: (a) Configuration of a 3-storey seismically isolated building, and (b) smooth bilinear inelastic model for the behavior of the seismic isolation system.

\section{PRACTICAL APPLICATION}

The linear viscoelastic model and its modifications that have been proposed in the literature are used to compare the response of a 3-storey base-isolated building due to poundings with the surrounding moat wall, under the Loma Prieta (UCSC 16 LGPC Station: Comp FN) and the Northridge (DWP 74 Sylmar - Converter Station: Comp FN) earthquakes. The impact stiffness is considered to be $2500 \mathrm{MN} / \mathrm{m}$, the coefficient of restitution is taken as 0.7 for all cases, while the mass of the surrounding moat wall is set to 500 tons.

Table 1 presents the peak responses of the base isolated structure with the separation gap equal to $20 \mathrm{~cm}$ for both excitations, considering the four aforedescribed impact models. The maximum impact velocities (both sides) and the impact incidences are also provided. It shall be noted that the number of impacts may deviate between the various models considered. In general, the differences in the computed responses for the linear viscoelastic and the Komodromos et al. models are very small. As expected, the two models have almost identical responses due to the fact that their only difference is in the tensile force during detachment. Nevertheless, there is a considerable variation of the peak base-floor acceleration computed considering the classic Kelvin-Voigt model and the corresponding results of the Ye et al. and the Pant and Wijeyewickrema models.

\begin{tabular}{|c|c|c|c|c|c|c|c|c|}
\hline \multirow[t]{2}{*}{ Peak Response } & \multicolumn{4}{|c|}{$\begin{array}{c}\text { Loma Prieta earthquake } \\
1989-10-18\end{array}$} & \multicolumn{4}{|c|}{$\begin{array}{c}\text { Northridge-01 earthquake } \\
1994-01-17\end{array}$} \\
\hline & 1 & 2 & 3 & 4 & 1 & 2 & 3 & 4 \\
\hline Base displacement $(\mathrm{cm})$ & 20.47 & 20.47 & 20.45 & 20.39 & 21.12 & 21.13 & 21.06 & 20.91 \\
\hline Top-floor displacement $(\mathrm{cm})$ & 23.60 & 23.60 & 23.60 & 23.56 & 28.14 & 28.15 & 28.11 & 28.01 \\
\hline Interstorey deflection $(\mathrm{cm})$ & 1.82 & 1.82 & 1.77 & 1.77 & 4.14 & 4.14 & 4.02 & 3.97 \\
\hline Base-floor acceleration $\left(\mathrm{m} / \mathrm{sec}^{2}\right)$ & 34.20 & 34.20 & 38.08 & 42.71 & 71.88 & 71.99 & 80.57 & 92.07 \\
\hline Top-floor acceleration $\left(\mathrm{m} / \mathrm{sec}^{2}\right)$ & 22.57 & 22.57 & 22.30 & 22.13 & 49.51 & 49.51 & 48.56 & 47.60 \\
\hline Remaining plastic deform. (cm) & - & 0.04 & - & - & - & 0.11 & - & - \\
\hline Max impact velocity $(\mathrm{m} / \mathrm{sec})$ & 0.48 & 0.48 & 0.48 & 0.48 & 1.06 & 1.06 & 1.06 & 1.07 \\
\hline \multirow{2}{*}{ Number of impacts (\#) } & 0 & 0 & 0 & 0 & 2 & 3 & 2 & 3 \\
\hline & 2 & 2 & 2 & 2 & 2 & 2 & 2 & 2 \\
\hline
\end{tabular}

1: Kelvin-Voigt model (Anagnostopoulos, 1988); 2: Modified Linear viscoelastic model (Komodromos et al., 2007); 3: Ye et al., 2009, 4: Pant and Wijeyewickrema,2012.

Table 1: Peak seismic responses of the 3-storey base isolated building with a seismic gap equal to $20 \mathrm{~cm}$, considering the 4 different impact models, under the Loma Prieta and the Northridge earthquakes. 
The origins of the observed variations can be clarified through Figure 4 and Figure 5. Specifically, these two figures present the impact force-indentation diagrams and the timehistories of the impact force at the base of the isolated building for the 4 different impact models, subjected to the Loma Prieta (Figure 4) and Northridge (Figure 5) excitations. Solid lines represent impacts on the left side of the building whereas dashed lines correspond to poundings on the right side. It is observed that the values of the maximum impact force calculated through the Kelvin-Voigt model and the modified version proposed by Komodromos et al. are essentially equal. This observation is also valid for the Northridge earthquake responses where the peak response occurs due to the second impact. However, the maximum impact force for the models proposed by Ye et al. and Pant and Wijeyewickrema is significantly higher. This deviation justifies the higher discrepancies among model responses observed in the base acceleration results (Table 1). Despite the large differences in the calculated impact forces the displacement response of the structure is found to be relatively insensitive to the actual model used.
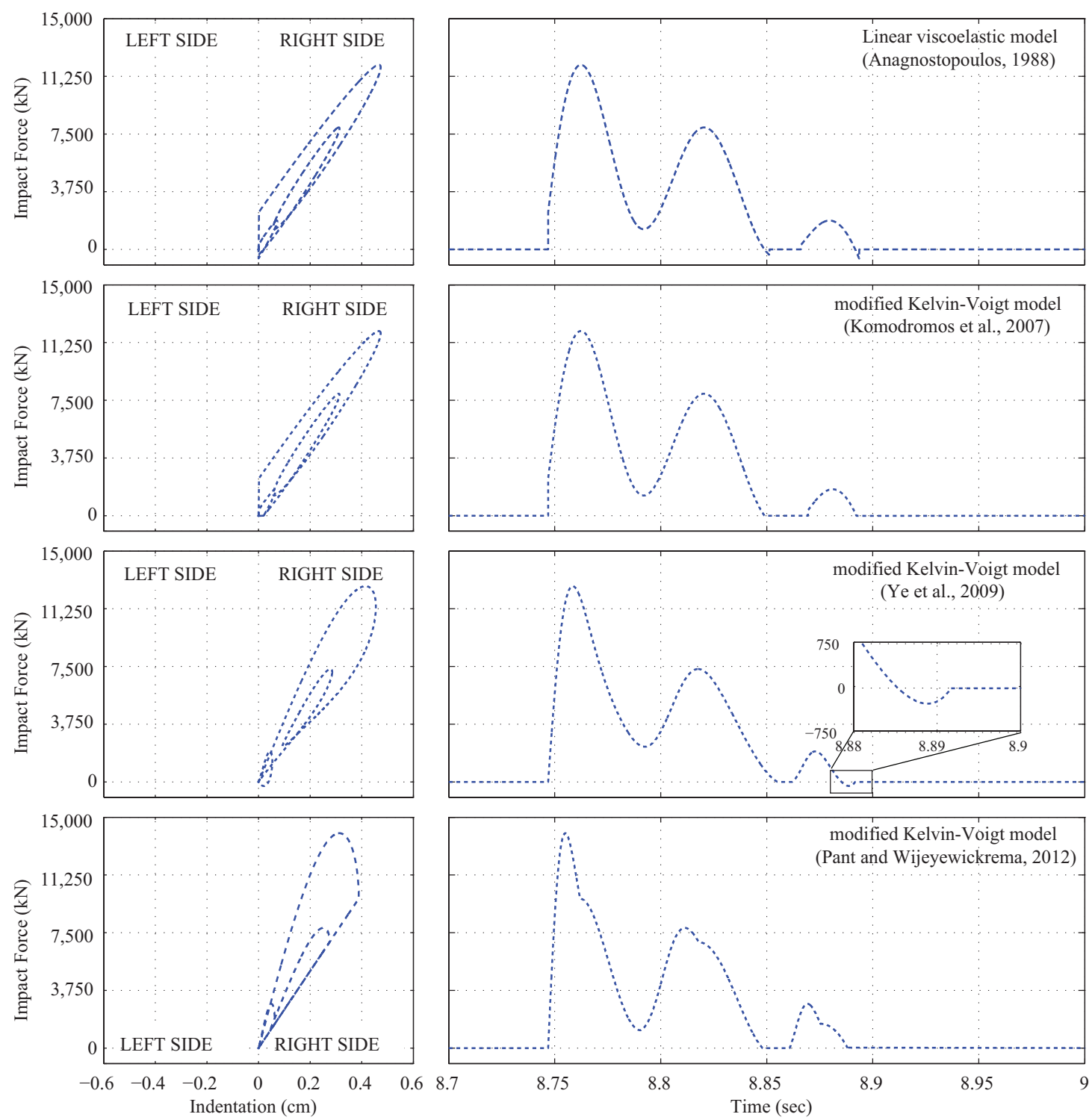

Figure 4: Plots of the impact force in terms of indentation and time-histories of the 3-storey base isolated building, under the Loma Prieta earthquake with a seismic gap equal $20 \mathrm{~cm}$, considering the 4 impact models. 
These simulations reveal that the utilization of the Ye et al. model does not always avoid the appearance of tensile force immediately before separation, which is consistent with the observations of Pant et al. [23]. The existence of tensile forces in the case of the Loma Prieta earthquake, as shown in Figure 4 (third row), is possible due to the activation of the dashpot element, which by definition is included in the restitution phase of contact. It should be noted, however, that in the case of the Northridge excitation (third row of Figure 5) the model does not produce tensile forces.
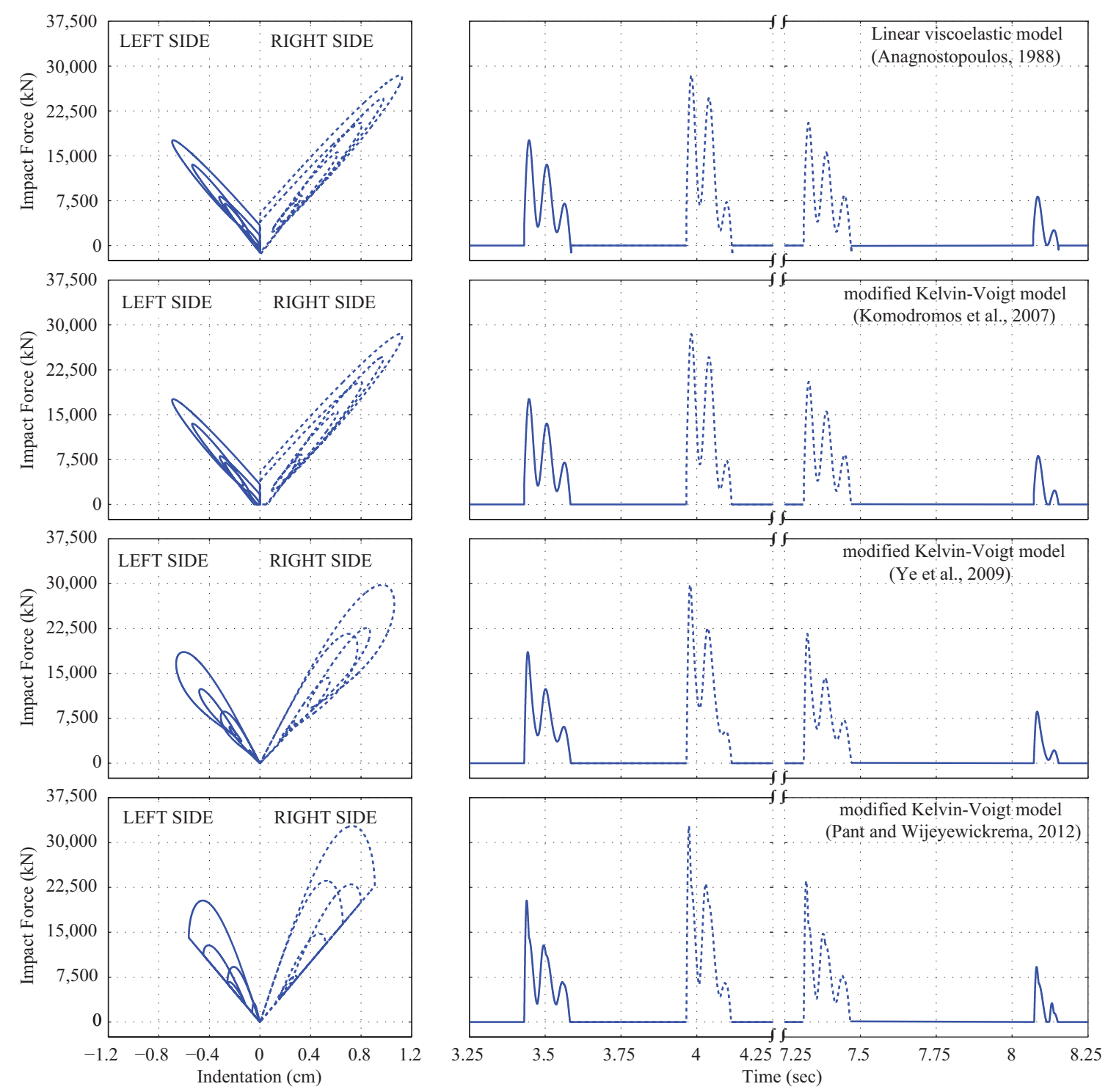

Figure 5: Plots of the impact force in terms of indentation and time-histories; of the 3-storey base isolated building under the Northridge earthquake with a seismic gap equal $20 \mathrm{~cm}$, considering different impact models.

\section{PARAMETRIC STUDIES AND NUMERICAL RESULTS}

A parametric study has been performed in order to examine the effects of the excitation characteristics on the dynamic response of the simulated base isolated building during poundings. Table 2 shows the five near-fault ground motions that have been used. The selected seismic accelerograms have been taken from the NGA database [24] and are expected to induce large displacements to the seismically isolated building, since they are characterized by low-frequency content, which is one of the most decisive factors for the occurrence of pound- 
ings in such structures. The response spectra of the five earthquakes' fault-normal component that has been used in this study are plotted in Figure 6.

\begin{tabular}{cllcc}
\hline NGA\# & Event & Station & Mw & PGA (g) \\
\hline 779 & Loma Prieta 1989-10-18 & UCSC 16 LGPC & 6.93 & 0.944 \\
821 & Erzican, Turkey 1992-03-13 & 95 Erzincan & 6.69 & 0.486 \\
828 & Cape Mendocino 1992-04-25 & CDMG 89156 Petrolia & 7.01 & 0.615 \\
1084 & Northridge-01 1994-01-17 & DWP 74 Sylmar - Converter Sta & 6.69 & 0.594 \\
2627 & Chi-Chi, Taiwan-03 1999-09-20 & CWB 99999 TCU076 & 6.2 & 0.524 \\
\hline
\end{tabular}

Table 2: Earthquake records that have been used in the performed simulations.
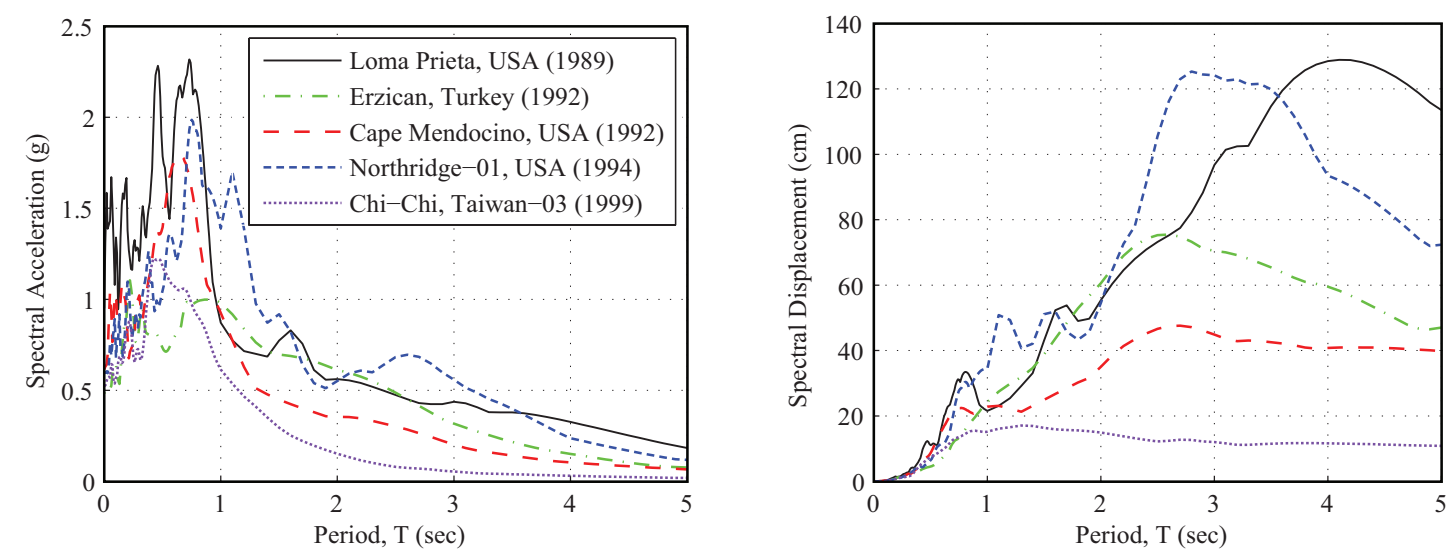

Figure 6: Acceleration and displacement response spectra of the fault normal components for the five earthquake records, considering a viscous damping ratio of $5 \%$.

\subsection{Effect of the gap size and the characteristics of the earthquake excitation}

The seismic gap width is systematically varied in the range of 10 to $35 \mathrm{~cm}$ with a step of $0.5 \mathrm{~cm}$, in order to investigate its effect on the overall response. The 3-storey base isolated building is analyzed under the selected near-fault ground motions, while the moat wall is assumed to be present on both sides of the building. Figure 7 shows the peak floor accelerations and the maximum inter-storey drifts of the base isolated building under the Loma Prieta earthquake as a function of the seismic gap width considering the four impact models. Each subplot corresponds to the response of a particular floor, or inter-storey response for the case of inter-storey deflections. It is apparent that the most severe peak floor accelerations occur at the base level where poundings occur. Subsequently, the maximum inter-storey deflections occur at the 1-0 interface.

The simulation results indicate that the peak absolute acceleration of the 3-storey base isolated building increase significantly due to structural impact, reaching values that are several times the PGA and can be more than 10 times the corresponding peak accelerations without pounding. The amplification of the inter-storey deflections due to structural poundings reaches values higher than 6 for a seismic gap of $10 \mathrm{~cm}$. Specifically, in that case the peak interstorey drifts exceed what the corresponding fixed-supported superstructure would experience $(0.026 \mathrm{~m})$. Furthermore, as the seismic gap increases, both peak floor accelerations and interstorey deflections of the superstructure significantly decrease. In particular, for relatively narrow gap widths the response is increasing with the width of the available clearance and, after a certain value, the response of the seismically isolated building begins to decrease as the seismic gap increases. 

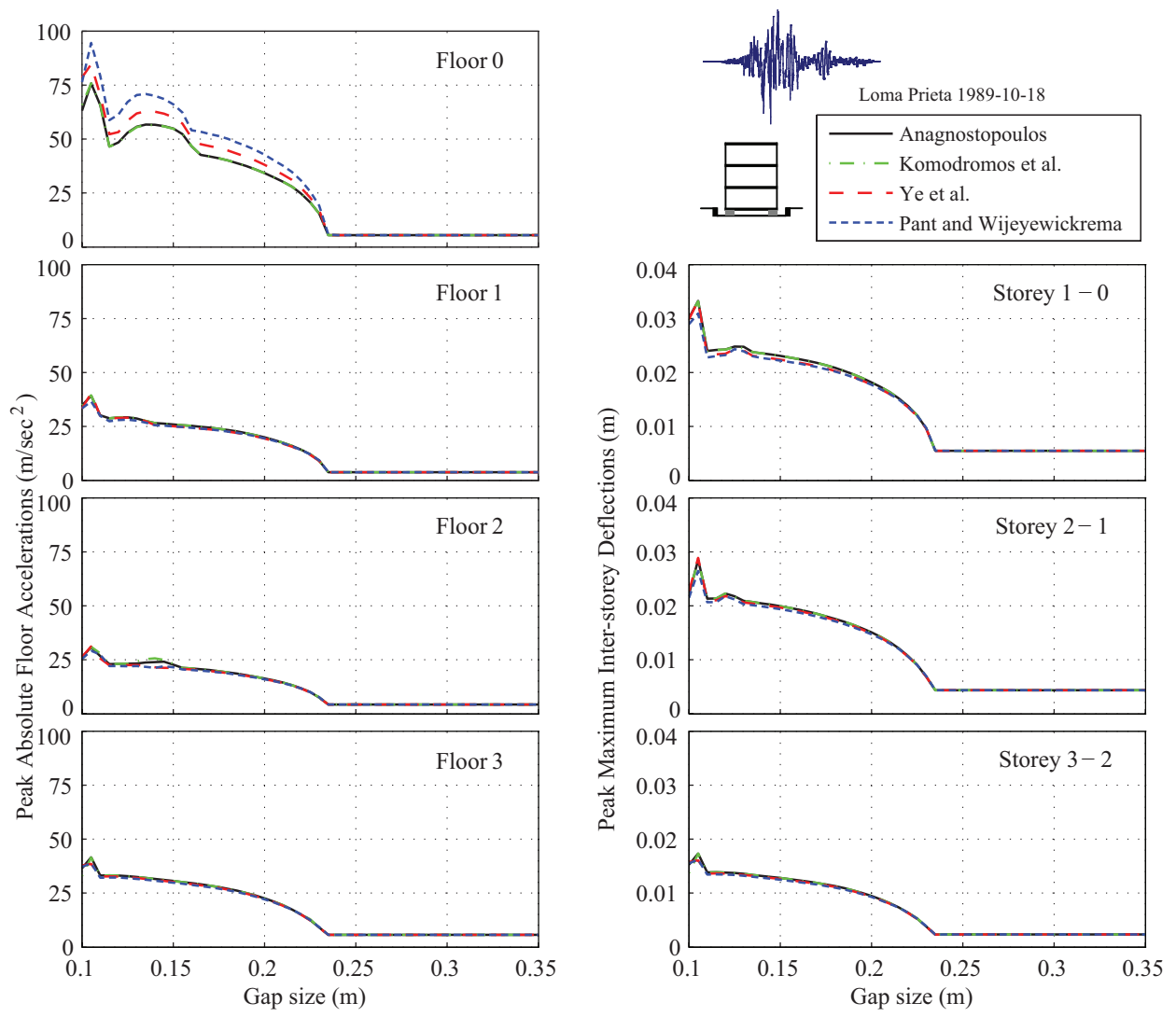

Figure 7: Maximum responses of the 3-storey base isolated building, under the Loma Prieta earthquake in terms of the width of the seismic gap, which varies from 10 to $35 \mathrm{~cm}$.

Figure 8 presents the peak values for indentation, impact velocity and impact force on both sides of the seismically isolated building for the Loma Prieta excitation, in terms of the width of the seismic. It is observed that the trends of the parameters under examination are very similar with the corresponding peak absolute floor acceleration at the impacting floor of the seismically isolated building, indicating that the amplification of the response due to impact is proportional to the impact velocity. It is also observed that, although the maximum impact velocity is relatively consistent between all four impact models considered, the predicted impact forces considering the modified contact models proposed by Ye et $a l$. and Pant and Wijeyewickrema are consistently higher.
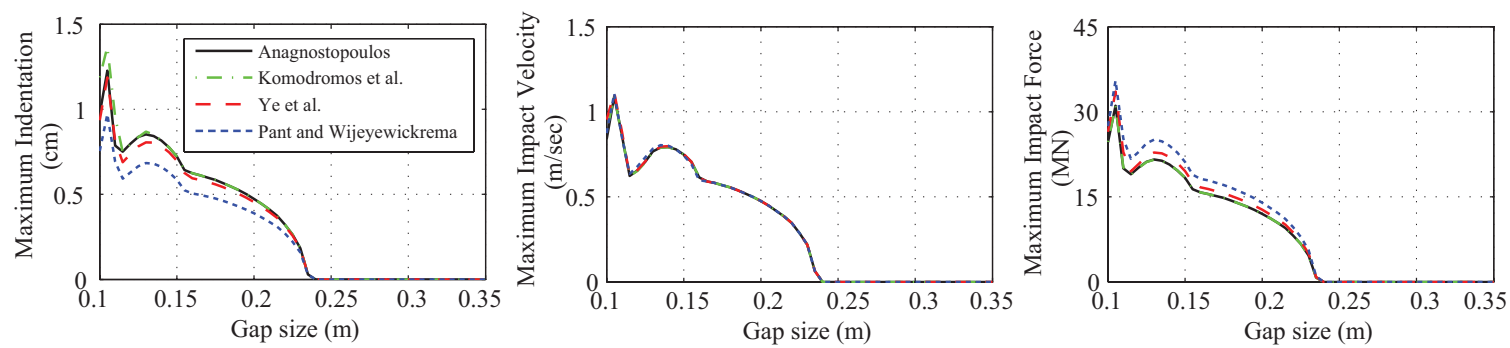

Figure 8: Maximum indentation, impact velocity and impact force of the seismically isolated building induced to the 3-storey structure subjected to Loma Prieta excitation, in terms of the width of the seismic gap.

The variation of the response of the 3-storey seismically isolated building due to the characteristics of the excitation is provided in Figure 9, where the envelope of peak responses is plotted for all considered earthquake excitations. It is observed that, in general and for a range 
of values of the width of the seismic gap near the maximum induced displacement, i.e. the critical gap size, the response is decreasing rapidly with the increment of the gap size. Overall, the four linear impact models that have been examined provide similar trends for the peak response of the superstructure.
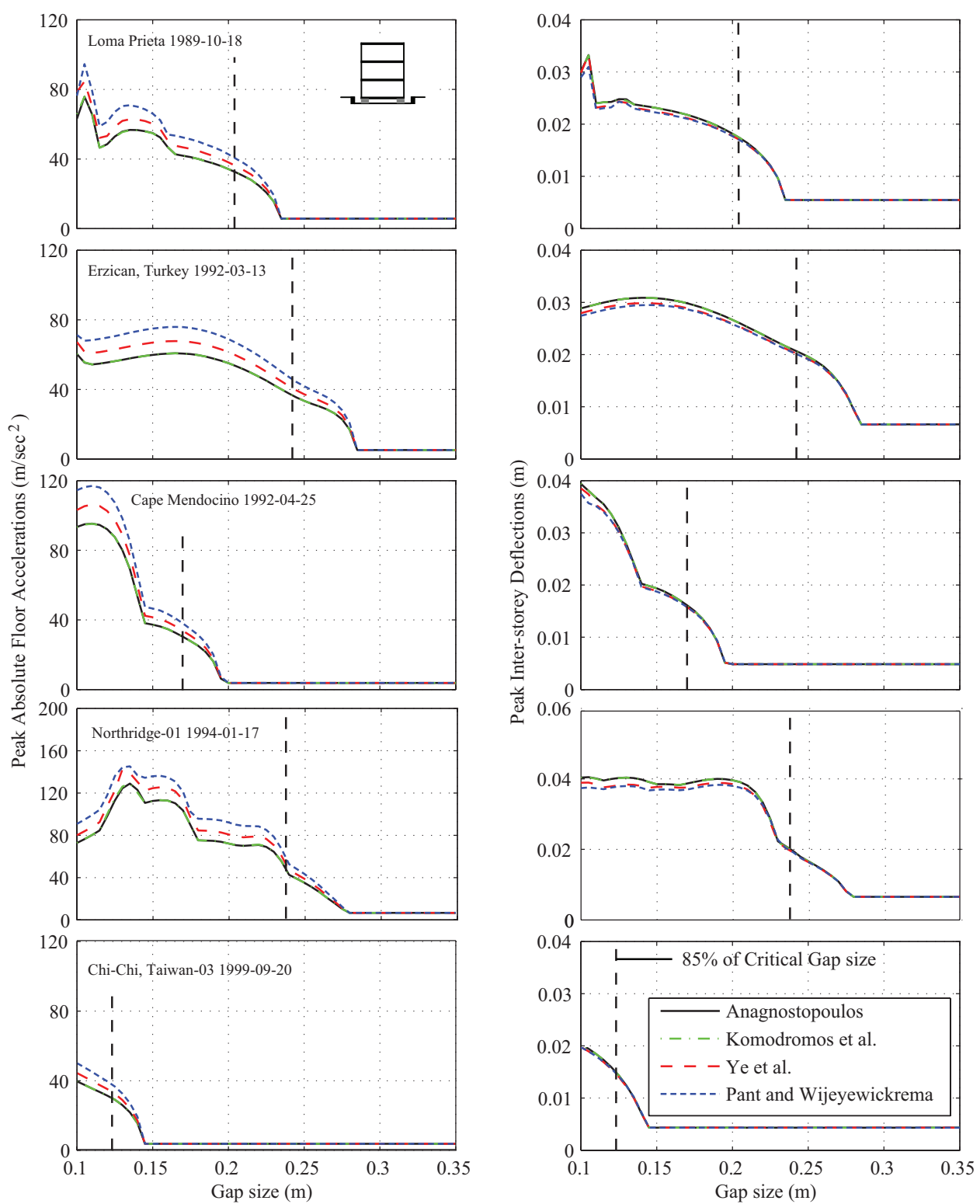

Figure 9: Maximum responses of the base isolated building, in terms of the width of the seismic gap, for the five selected earthquakes considering the 4 impact models under consideration.

In order to compare the results among the four impact models, all peak responses are normalized with respect to the classical Kelvin-Voigt model (i.e. using the formula provided by Anagnostopoulos for the estimation of the impact damping coefficient). Figure 10 presents the normalized peak absolute floor accelerations, showing that the Kelvin-Voigt impact model and the modified linear viscoelastic model proposed by Komodromos et al., in which a permanent deformation is allowed, lead to almost identical responses. The interstorey drifts are, in general, underestimated up to $7.5 \%$ for relatively narrow gap sizes, when the modified linear models proposed by the Ye et al. and Pant and Wijeyewickrema are used, compared to the corresponding peak responses computed using the classical Kelvin-Voigt model. In general, 
the underestimation of the peak response while using the two modified models tends to decrease with the increase of the width of the seismic gap. Additionally, for a seismic gap $15 \%$ smaller than the maximum unobstructed displacement under each one of the selected nearfault ground motions the deviation of the peak response is similar. The overestimation of the peak accelerations fluctuate around 10.0 and $25.0 \%$ when the contact elements proposed by Ye et al. and the Pant and Wijeyewickrema, respectively, are used.
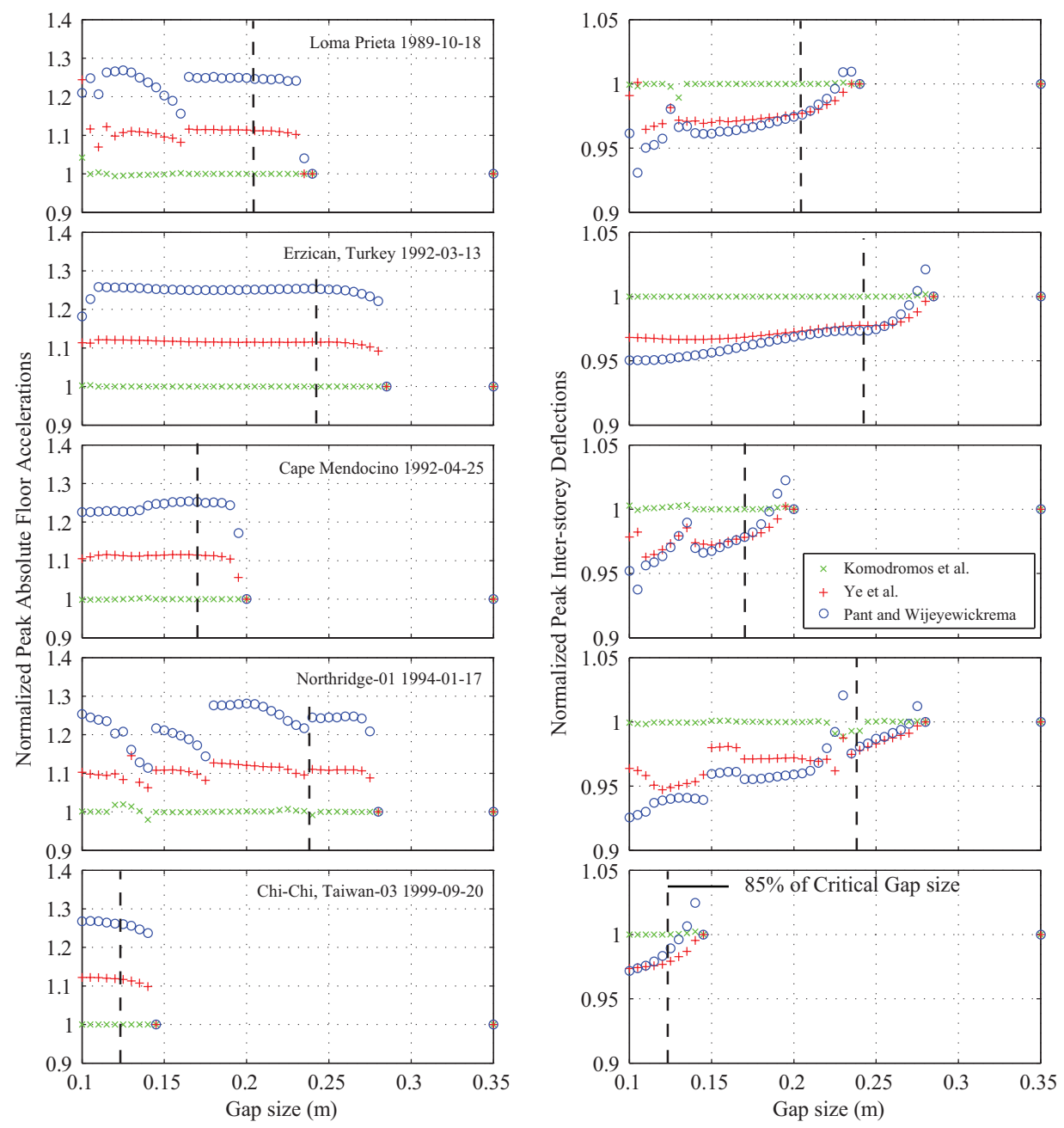

Figure 10: Peak response using the modified linear impact models normalized to the corresponding peak response obtained with the classical Kelvin-Voigt model in terms of the width of the seismic gap.

\subsection{Effect of the impact parameters}

In order to examine the effect of the impact stiffness and the coefficient of restitution on the peak seismic response of the base isolated building during poundings, another series of parametric studies is performed. For this investigation the 3-storey base isolated building is simulated, assuming a seismic gap $15 \%$ smaller than the maximum unobstructed displacement under each one of the selected near-fault ground motions, in order to ensure structural pounding. The widths of the seismic gap size that have been used in the simulations have been marked in Figure 9. The impact stiffness, $k_{k}$ of the linear impact spring is varied in the range of 500 to $5000 \mathrm{kN} / \mathrm{mm}$, while the coefficient of restitution is varied between 0.3 and 1.0 . The variation of the amplification of peak floor accelerations and peak inter-storey deflections 
of the 3-storey base isolated building that are computed considering the classic Kelvin-Voigt model in terms of the two impact parameters, are presented in the next graphs.

The peak absolute floor accelerations due to pounding of the seismically isolated building with the moat wall under each one of the selected near-fault ground motions, as presented in Figure 11(a), tend to increase for high values of the impact stiffness. Please note that there is a correspondence between the line-type used to plot Figure 11(a) with the excitation shown in the subplots of Figure 11(b). The results indicate that when the impact stiffness ranges up to the value of $\sim 1200 \mathrm{kN} / \mathrm{mm}$, which corresponds to 2 times the superstructure's storey stiffness, the inter-storey deflections increase rapidly, while for the rest of the examined range the peak response remain almost insensitive to this parameter. The simulation results also reveal that the excitation characteristics influence considerably the amplification of the peak response.

(a)

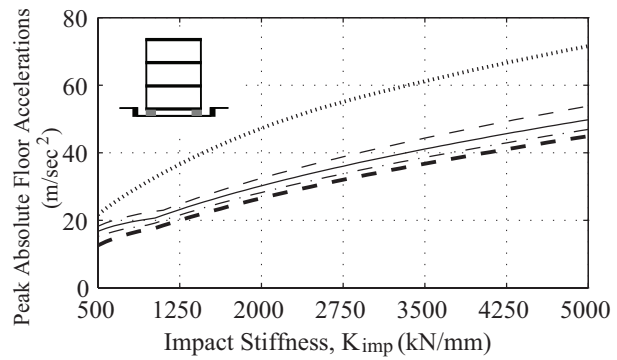

(b)

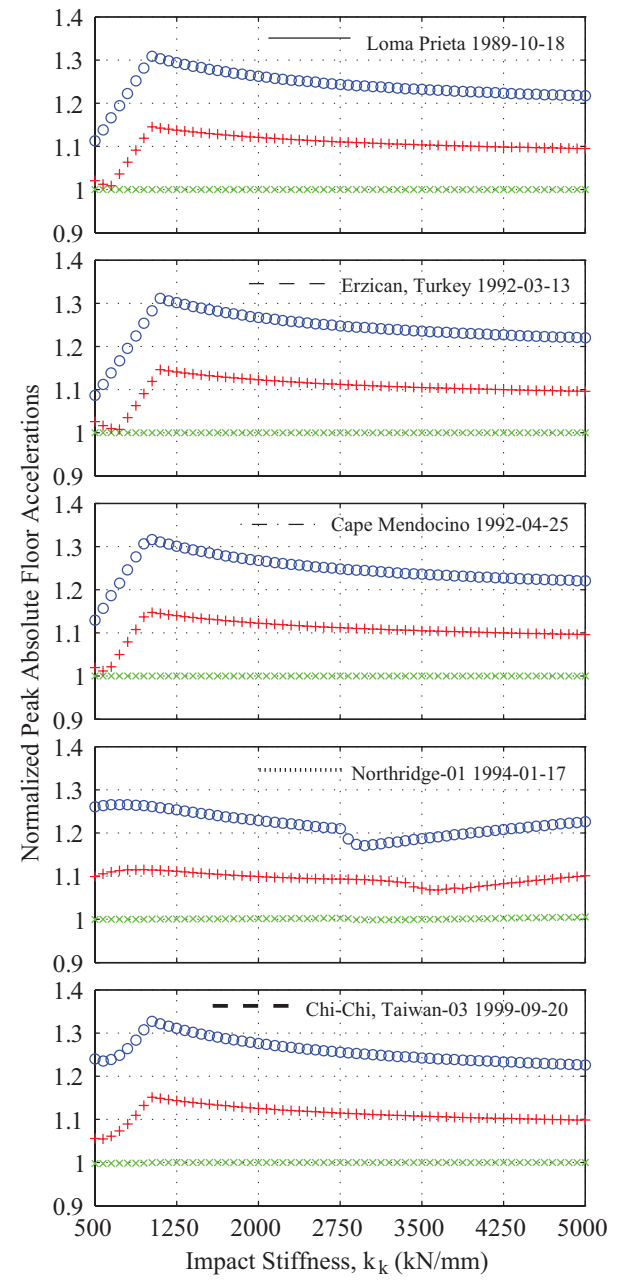

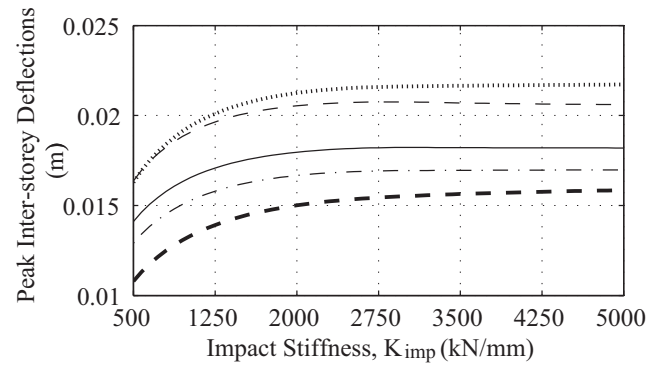
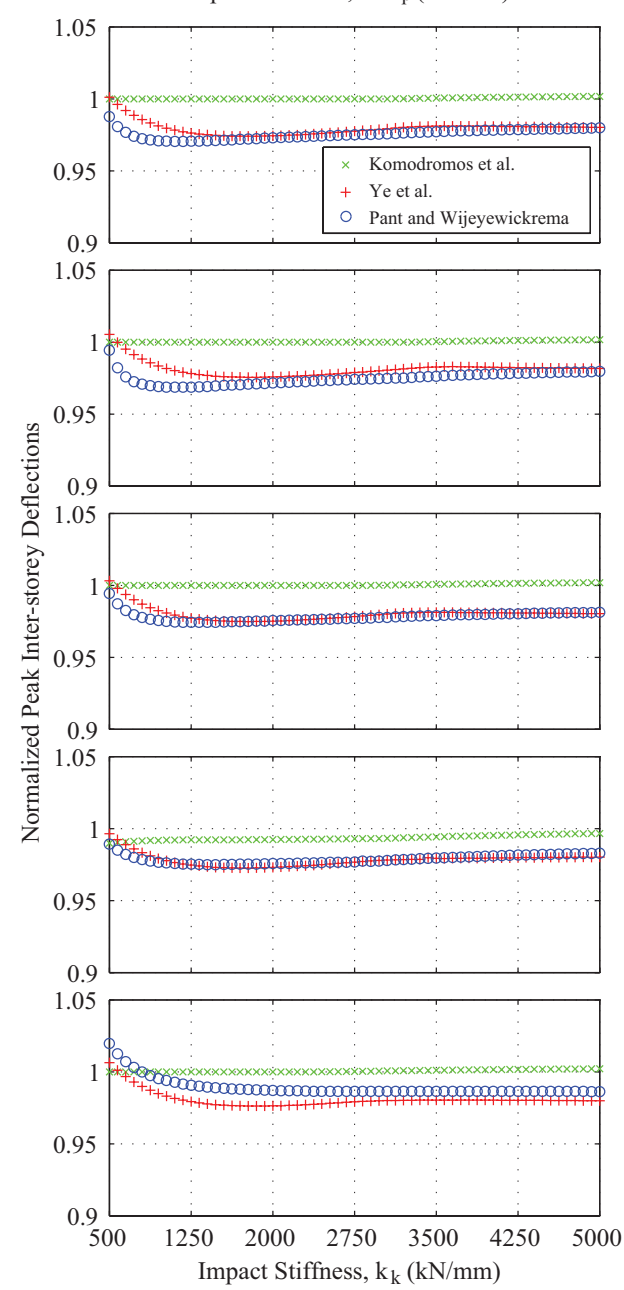

Figure 11: Influence of the impact stiffness on the (a) peak response considering the Kelvin-Voigt contact element and (b) normalized peak response considering modified linear impact models, for each earthquake record. 
Figure 11(b) shows the normalized peak response of the modified linear impact models considering as reference model the linear viscoelastic widely used by Anagnostopoulos. The results indicate that the peak responses from the classical Kelvin-Voigt and the modified by Komodromos et al. models are similar. Furthermore, the peak inter-storey drifts considering models proposed by Ye et al. and Pant and Wijeyewickrema, although they use different methodologies to represent impact, lead to an underestimation of the response of $2.5 \%$ for impact stiffness higher than $1200 \mathrm{kN} / \mathrm{mm}$. On the other hand, using the aforementioned models lead to an overestimation of the peak absolute acceleration up to 15 and 33\%, respectively. It can be generally observed that the peak floor accelerations are directly proportional to the impact stiffness for low values of $k_{k}$ (approx. $k_{k}<1000 \mathrm{kN} / \mathrm{mm}$ ). As the impact stiffness increases this dependency fades away and the peak floor accelerations tend to become constant for all floors with the exception of the base floor response, which maintains a strong dependency. These reported characteristics appear to hold for both Loma Prieta and Northridge excitations, which are presented in Figure 12. Furthermore, these results shed light on the origin of the kinks appearing in Figure 11(b), which relate to an interchange between the floors that dominate the global structural response, i.e. for low values of $k_{k}$ (Loma Prieta excitation) the third floor appears to deliver the peak floor acceleration, whereas as $k_{k}$ increases the response is dominated by the base floor accelerations, which is the level impact occurs.
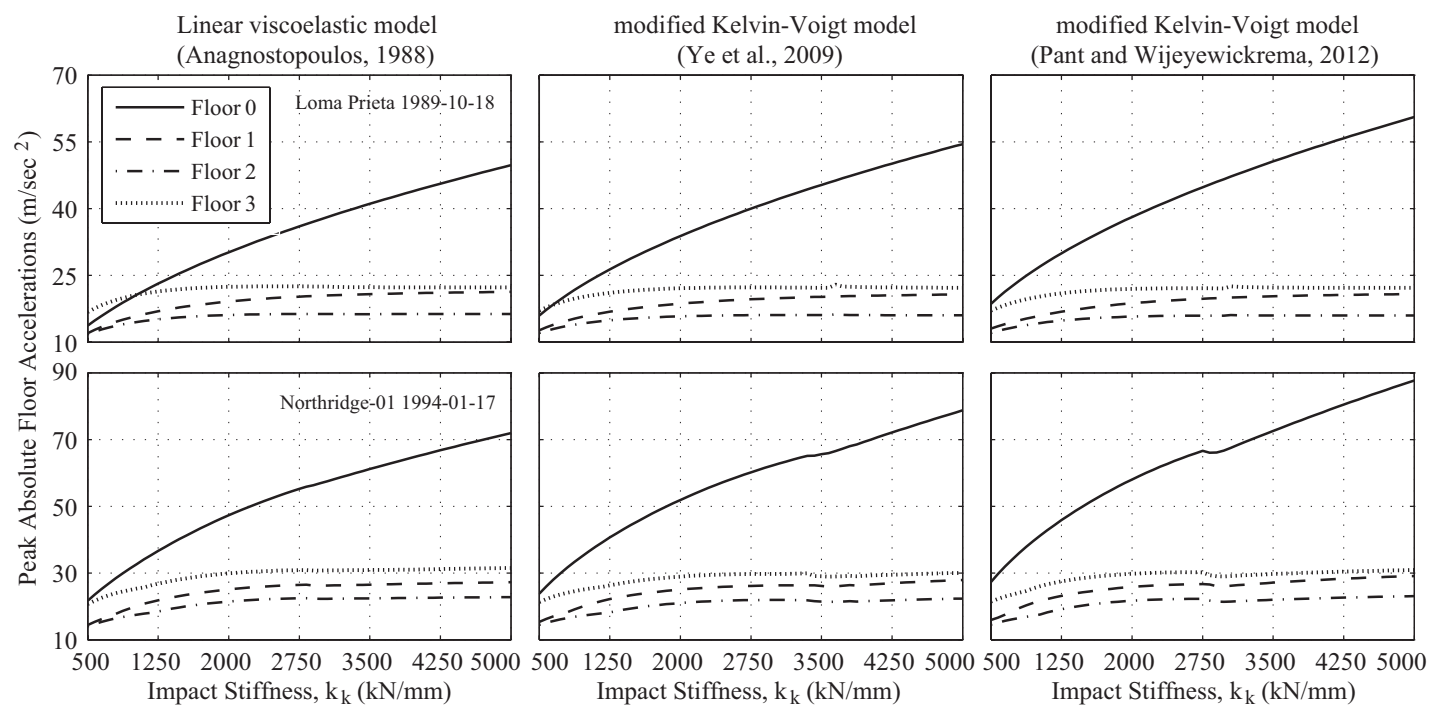

Figure 12: Influence of the impact stiffness on the peak floor accelerations under near-fault ground motions.

Figure 13 presents the first impact incidence obtained from the time-history analysis carried out for the Loma Prieta ground motion considering different linear contact elements for various values of the impact stiffness. It should be noted that for this particular excitation the first impact incidence delivers the peak responses. The results highlight the significant influence of the impact stiffness on the peak impact force due to pounding with the adjacent moat wall. In general, large peak forces are coupled with higher values of the impact stiffness and small deformations across all three impact models. It is apparent that the models proposed by Ye et al. and Pant and Wijeyewickrema, produce higher magnitude impact forces than the linear viscoelastic model mainly due to the damping of the contact elements. 

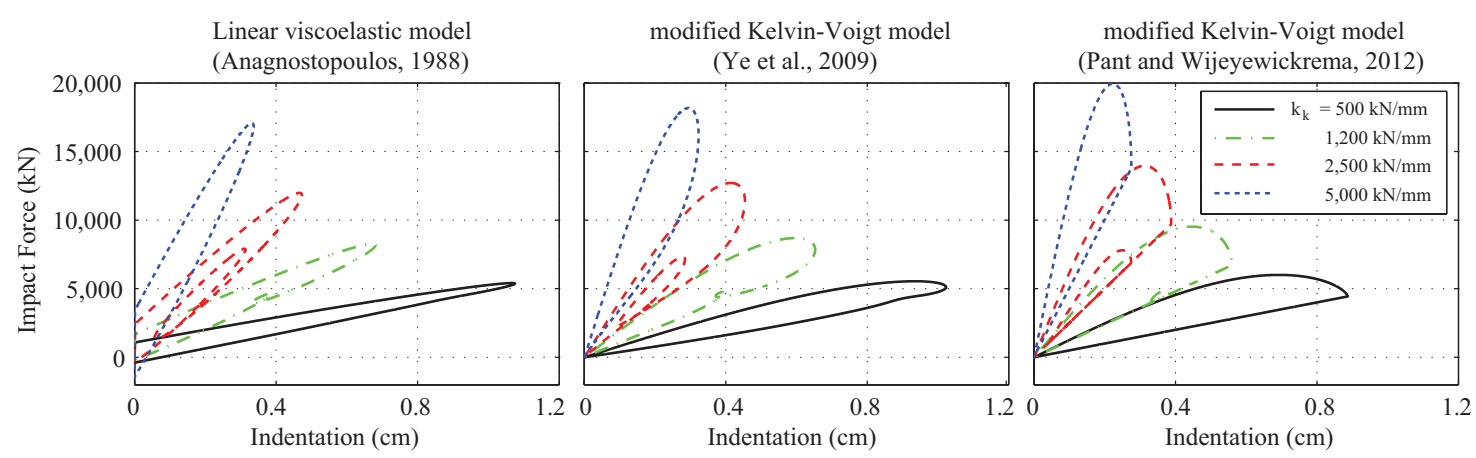

Figure 13: Plots of impact force introduced to the 3-storey seismically isolated building during the first incidence in terms of indentation considering different impact stiffnesses.

The variation of peak responses of the 3-storey base isolated building in terms of the coefficient of restitution under the five ground motions is presented in Figure 14(a). It is observed that for values lower than 0.4, the peak floor accelerations increase, reaching their maximum values when the impact becomes highly overdamped. In general, the excitation characteristics influence considerably the magnitude of the response. Figure 14(b) shows the normalized peak response of the linear impact models with respect to the classical Kelvin-Voigt model.

The results indicate that the minor modification proposed by Komodromos et al. does not significantly influence the accuracy of the impact model. Furthermore, the peak inter-storey drifts computed while using the models proposed by Ye et al. and Pant and Wijeyewickrema, lead to an underestimation of the response up to 7.5 and $5.0 \%$, respectively, with respect to the peak responses computed using the classical Kelvin-Voigt model. For all cases, the underestimation of the peak inter-storey deflections tends to decrease with the increase of the coefficient of restitution. On the other hand, employing the aforementioned models lead to a significant overestimation of the peak absolute floor acceleration.

The enclosed areas between the loading and unloading curves of an impact-force vs. indentation curve, define the amount of energy dissipated during the impact. As we can see from the first subplot in Figure 15, the coefficient of restitution does not influence considerably the peak impact force for the linear viscoelastic model. On the other hand, the peak impact force considering the recommended modifications by Ye et al. and Pant and Wijeyewickrema depends significantly on the coefficient of restitution (as shown in the second and third columns of Figure 15). Such a deviation of the peak impact force, especially for lower values of the coefficient of restitution, lead to an overestimation of the peak absolute floor acceleration, i.e. of the magnitude of 2.75 and 1.6 for $e=0.3$, when utilizing the Ye et al. and Pant and Wijeyewickrema models, respectively. 
(a)

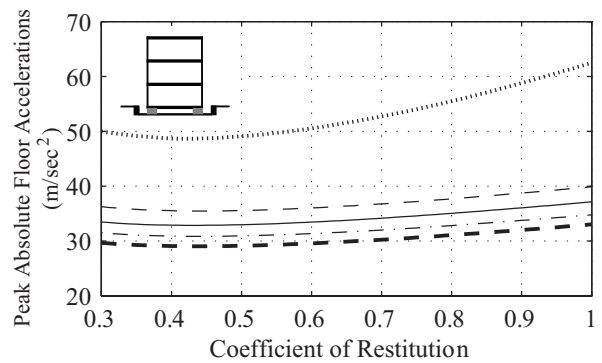

(b)

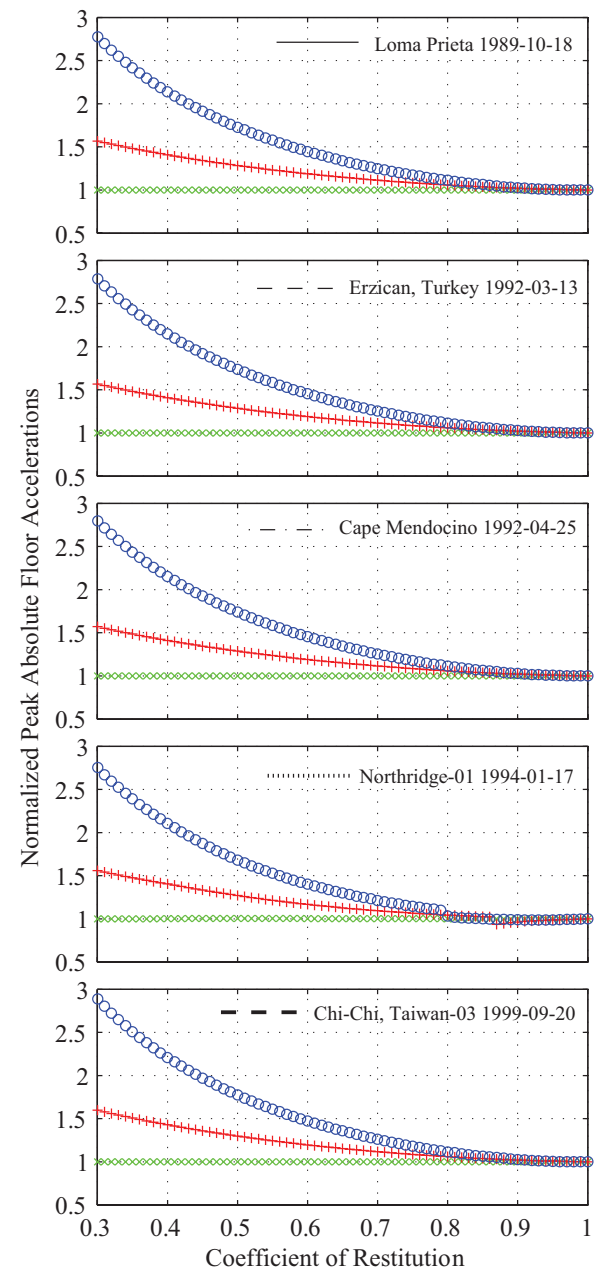

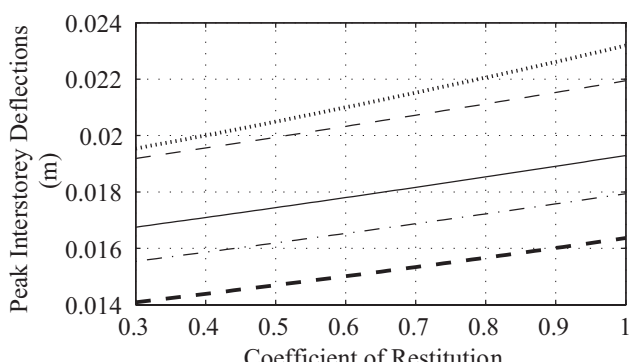

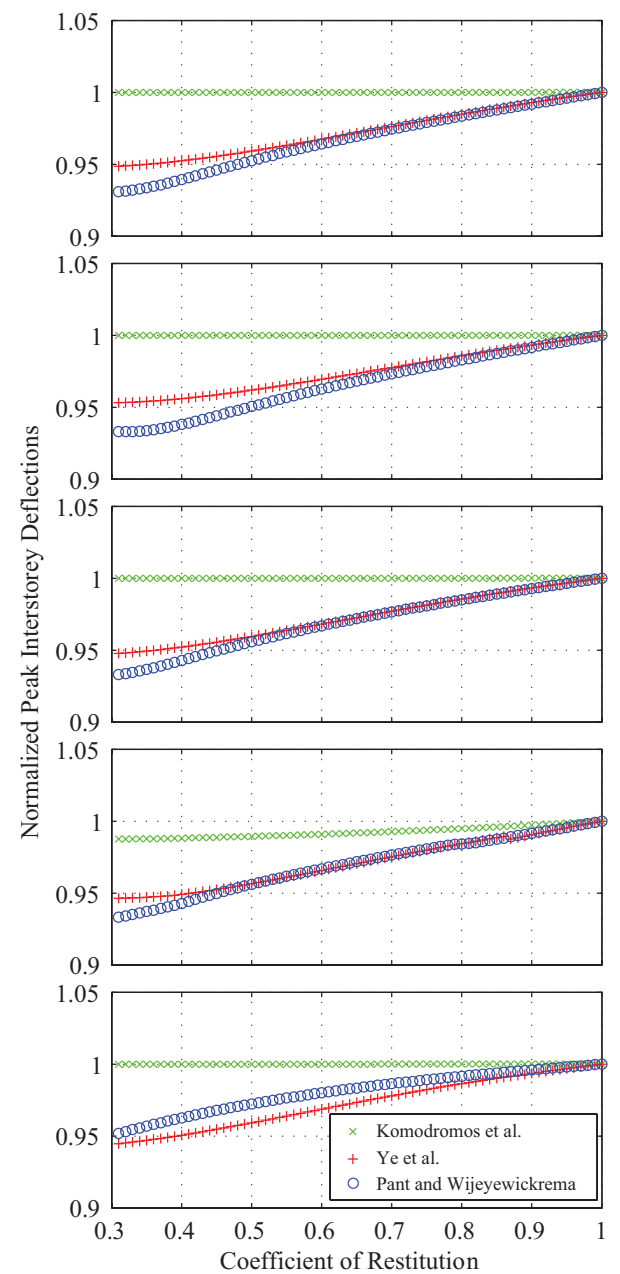

Figure 14: (a) Peak response considering the Kelvin-Voigt contact element and (b) normalized peak response considering modified linear impact models, in terms of coefficient of restitution, $e$.
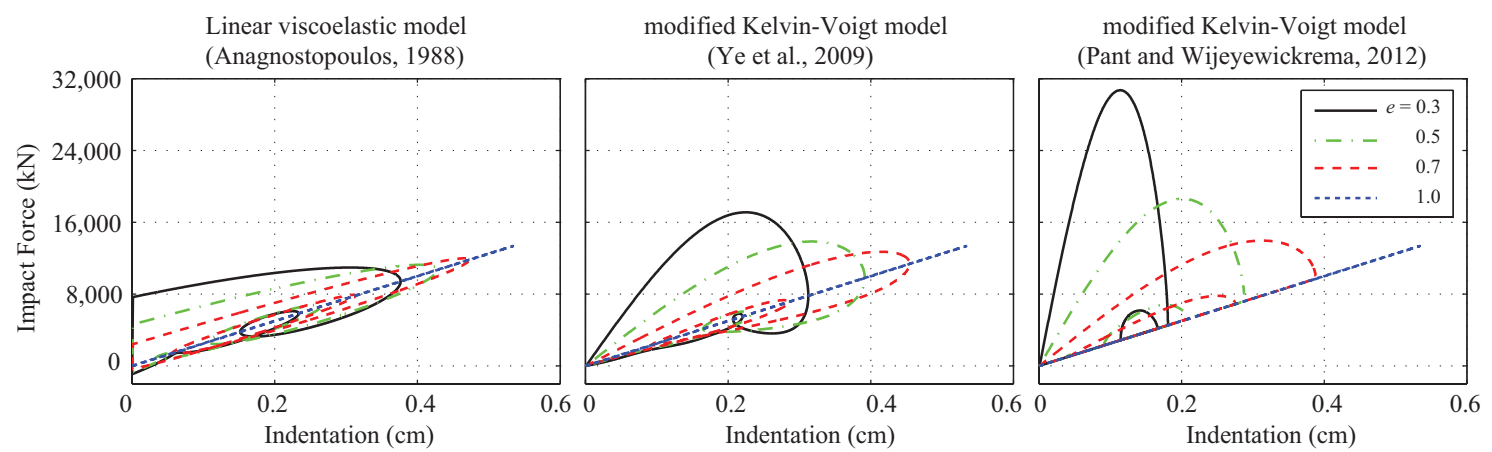

Figure 15: Plots of the impact force introduced to the 3-storey seismically isolated building during the first incidence in terms of indentation, under the Loma Prieta earthquake considering different coefficients of restitutions. 


\section{CONCLUSIONS}

The seismic performance of a typical 3-storey seismically isolated building with the surrounding moat wall has been evaluated using near-fault pulse-like ground motions. Three recently proposed variations of the linear viscoelastic contact model have been compared considering as a base model the classical Kelvin-Voigt model using the formula provided by Anagnostopoulos for the estimation of the impact damping coefficient. The relative performance of the structure has been evaluated based on the peak absolute floor accelerations and inter-storey drifts for various gap sizes and different impact parameters.

The following conclusions are drawn for the building and the ground motions considered in this research study:

- Although the modified linear viscoelastic model by Ye et al. was introduced to provide a reasonable physical explanation of the pounding mechanism, it does not always prevent the appearance of tensile force just before the end of the contact.

- The minor modification proposed by Komodromos et al. for the linear viscoelastic model does not influence considerably the peak response values.

- The maximum impact forces obtained using the linear impact models proposed by Ye et al. and Pant and Wijeyewickrema are much higher than those obtained using the linear viscoelastic model with the formula provided by Anagnostopoulos, leading to a significant overestimation of the peak absolute accelerations.

- The inter-storey deflections of the building are, in general, underestimated when the impact models proposed by Ye et al. and Pant and Wijeyewickrema are used. Moreover, the normalized response ratios of the inter-storey drifts appear to increase with a decreasing gap size and coefficient of restitution.

\section{REFERENCES}

[1] R. I. Skinner, W. H. Robinson, and G. H. McVerry, An introduction to seismic isolation. West Sussex, UK: John Wiley \& Sons Ltd, 1993.

[2] F. Naeim and J. M. Kelly, Design of seismic isolated structures: From theory to practice. Hoboken NJ, USA: John Wiley \& Sons Inc, 1999.

[3] P. Komodromos, Seismic Isolation for Earthquake Resistant Structures. Southampton, 2000.

[4] S. Nagarajaiah and X. Sun, "Base-Isolated FCC Building: Impact Response in Northridge Earthquake”, J. Struct. Eng., 127 (9), 1063-1075, 2001.

[5] P. K. Malhotra, "Dynamics of seismic impacts in base-isolated buildings", Earthq. Eng. Struct. Dyn., 26 (8), 797-813, 1997.

[6] H. C. Tsai, "Dynamic analysis of base-isolated shear beams bumping against stops", Earthq. Eng. Struct. Dyn., 26 (5), 515-528, 1997.

[7] V. A. Matsagar and R. S. Jangid, "Seismic response of base-isolated structures during impact with adjacent structures", Eng. Struct., 25 (10), 1311-1323, 2003.

[8] P. Komodromos, P. C. Polycarpou, L. Papaloizou, and M. C. Phocas, "Response of seismically isolated buildings considering poundings", Earthq. Eng. Struct. Dyn., 36 (12), 1605-1622, 2007.

[9] P. Komodromos, "Simulation of the earthquake-induced pounding of seismically isolated buildings", Comput. Struct., 86 (7-8), 618-626, 2008. 
[10] D. R. Pant and A. C. Wijeyewickrema, "Structural performance of a base-isolated reinforced concrete building subjected to seismic pounding", Earthq. Eng. Struct. Dyn., 41 (12), 1709-1716, 2012.

[11] D. R. Pant and A. C. Wijeyewickrema, "Performance of base-isolated reinforced concrete buildings under bidirectional seismic excitation considering pounding with retaining walls including friction effects", Earthq. Eng. Struct. Dyn., 43 (10), 1521-1541, 2014.

[12] P. C. Polycarpou, L. Papaloizou, and P. Komodromos, "An efficient methodology for simulating earthquake-induced 3D pounding of buildings", Earthq. Eng. Struct. Dyn., 43 (7), 985-1003, 2014.

[13] S. A. Anagnostopoulos, "Pounding of buildings in series during earthquakes", Earthq. Eng. Struct. Dyn., 16, 443-456, 1988.

[14] R. Jankowski, "Non-linear viscoelastic modelling of earthquake-induced structural pounding”, Earthq. Eng. Struct. Dyn., 34 (6), 595-611, 2005.

[15] K. Ye, L. Li, and H. Zhu, "A modified Kelvin impact model for pounding simulation of base-isolated building with adjacent structures", Earthq. Eng. Eng. Vib., 8 (3), 433-446, 2009.

[16] K. Ye, L. Li, and H. Zhu, "A note on the Hertz contact model with nonlinear damping for pounding simulation," Earthq. Eng. Struct. Dyn., 38 (9), 1135-1142, 2009.

[17] S. Muthukumar and R. DesRoches, "A Hertz contact model with non-linear damping for pounding simulation", Earthq. Eng. Struct. Dyn., 35 (7), 811-828, 2006.

[18] R. C. Barros, H. Naderpour, S. M. Khatami, and A. Mortezaei, "Influence of Seismic Pounding on RC Buildings with and without Base Isolation System Subject to NearFault Ground Motions", J. Rehabil. Civ. Eng., 1 (1), 39-52, 2013.

[19] S. A. Anagnostopoulos and K. V. Spiliopoulos, "An investigation of earthquake induced pounding between adjacent buildings", Earthq. Eng. Struct. Dyn., 21 (4), 289$302,1992$.

[20] R. Jankowski, K. Wilde, and Y. Fujino, "Pounding of superstructure segments in isolated elevated bridge during earthquakes", Earthq. Eng. Struct. Dyn., 27 (5), 487-502, 1998.

[21] P. Zhu, M. Abe, and Y. Fujino, "Modelling three-dimensional non-linear seismic performance of elevated bridges with emphasis on pounding of girders", Earthq. Eng. Struct. Dyn., 31 (11), 1891-1913, 2002.

[22] E. Mavronicola and P. Komodromos, "On the response of base-isolated buildings using bilinear models for LRBs subjected to pulse-like ground motions: sharp vs. smooth behaviour", Earthq. Struct., 7 (6), 1223-1240, 2014.

[23] D. R. Pant, A. C. Wijeyewickrema, and T. Ohmachi, "Seismic Pounding between Reinforced Concrete Buildings: A Study using two recently proposed Contact Element Models", in 14th European Conference on Earthquake Engineering, 2010.

[24] PEER Pacific Earthquake Engineering Research Center, "Ground motion database," 2011 [Online]. Available: http://peer.berkeley.edu/peer_ground_motion_database. 